\title{
Growth of Cast Iron in Austenite Region*
}

\author{
By Kingo Nagaoka**
}

\section{Synopsis}

A grey cast iron increases its volume irreversibly without transformation and graphitization by a cyclic heating in its austenite region. The present investigation is intended to explain some experimental facts obtained concerning the growth of cast iron in air, which could not be made clear by the earlier theories. Therefore, a new mechanism of growth, suggested by the author, was applied to explain them. The results derived from this investigation can be summarized as follows:

(1) Growth in the austenite region depends mainly on the difference between the upper and lower temperatures of the cyclic heating.

(2) Even a hard grey cast iron that does not grow in the critical range may grow in the austenite region.

(3) When a nodular graphite cast iron is subjected to a cyclic heating in its austenite region, it shows a gradual growth by drawing loops on its dilatometer curves.

(4) Preheating in air promotes the growth in the austenite region, but retards the growth in the critical range.

(5) The growth characteristics of cast iron differ in the critical range and in the austenite region. And the growth resulting from a cyclic heating covering the both regions is the sum of the two kinds of growth in their separate regions.

(6) It is suggested that the migration of graphite carbon during the process of a cyclic heat treatment in the austenite region can be a factor of creating the irreversible volume changes.

\section{Introduction}

Many theories have been proposed to explain the mechanism of growth of cast iron. It is widely recognized, however, that the growth must be caused mainly by the graphitization of carbide, oxidation effects, pressure of occluded gas and crack formation. It was stated by Kikuta ${ }^{1)}$ that the initial growth in the first step of heating was due to graphitization and in the subsequent heating it was attributed to the formation of fissures near the graphite flakes originated by irregular expansion and contraction in the process of heating and cooling through the critical temperature range, which would be accelerated by oxidation. The excellent characteristics of growth of hard cast iron containing stable carbide and nodular graphite cast iron were explained by these complicated theories.

The growth of cast iron is related to the transformation, graphitization and oxidation in heating, but the growth in the austenite region takes place without any transformation and graphitization of carbide. For the purpose of explaining the growth of the latter case, Sawamura ${ }^{2)}$ applied the oxidation theory and $\bar{O} k \bar{o} \mathrm{chi}^{3)}$ attributed the growth to the pressure of occluded gas. However, the growth in the austenite region has never been investigated as an independent problem. In the present work some experimental facts were obtained concerning the growth in the austenite region. In order to explain these facts, a mechanism of growth formerly suggested by the present author ${ }^{4}$ was applied. The mechanism differs from the earlier theories, and is confirmed by the present investigation to be applicable to the growth in the austenite region. In this conception, the migration of graphite carbon during the process of heating and cooling is regarded as the main source of the growth. The author has reported, in the previous reports, ${ }^{4), 5)}$ that a phenomenon of redistribution of graphite can be observed in microstructure of grown cast irons, on which a new mechanism of growth can be constructed.

\section{Experimental Procedure}

In order to measure the growth in the austenite region at high temperature, a dilatometer was constructed. The schematic view of the dilatometer is illustrated in Fig. 1. Growth of cast iron is affected

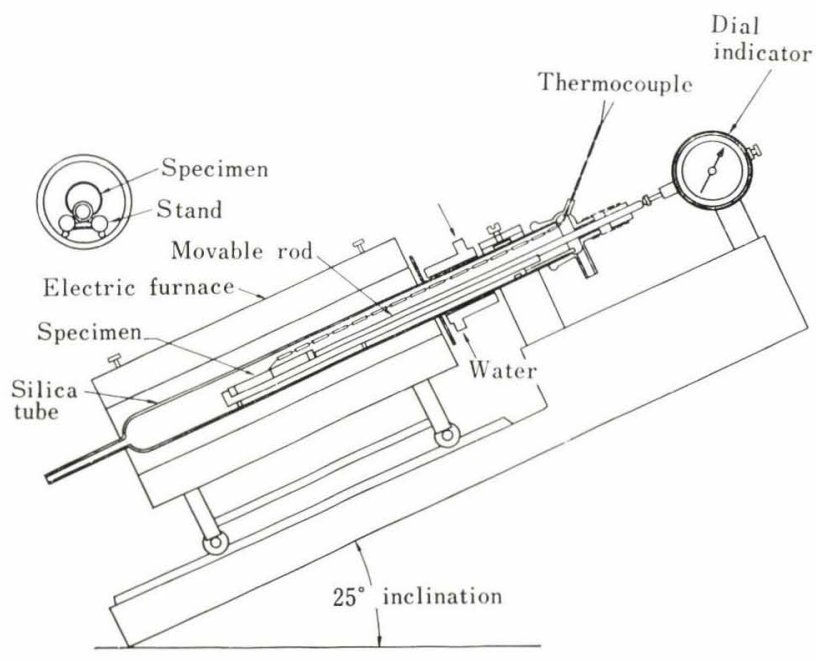

Fig. 1. Schematic view of dilatometer

by oxidation, but the previous investigation ${ }^{6)}$ revealed that the growth characteristics of cast iron can not be determined in a vacuum of $10^{-3} \mathrm{~mm} \mathrm{Hg}$. So in this experiment all tests were carried out in air in a silica tube closed at the both ends.

A test piece on the stand was heated in an electric furnace and a linear change of the test piece during the process of heating was indicated on a dial-

* This article is in reference to the lecture delivered before the 56th Grand Lecture Meeting of The Iron \& Steel Institute of Japan held in April 1958 in Tokyo. Japanese text was received on August 13, 1963 and printed in Tetsu-to-Hagané (Journal, Iron \& Steel Institute, Japan), 50 (1964), 5, 773-781.

** Prof.-Dr. Eng., Hokkaido University. 
indicator with a movable silica rod mediated between them. The foundation of the apparatus is inclined to keep the indication exact. The temperature of the test piece was measured by a thermocouple tied at its side, and the average rate of heating and cooling was $10^{\circ} \sim 12^{\circ} \mathrm{C} / \mathrm{min}$ in the range of $800^{\circ} \rightleftarrows 900^{\circ} \mathrm{C}$.

The test pieces, each $9 \mathrm{~mm}$ dia. $\times 75 \mathrm{~mm}$ long, were machined from foundry cast irons selected for this experiment. Iron $T$ is a nodular graphite cast iron and the others are flake graphite cast irons. The chemical compositions are shown in Table 1 .

\section{Results and Discussions}

\section{Effects of Heating Cycles}

When a specimen is held isothermally at a temperature in the austenite region, its volume increases or decreases according to the quality of cast iron and the heating atmosphere. In the case of a cyclic heating, the growth of cast iron takes place both in the austenite region without transformation and in the critical range with transformation. The tests of linear growth for different heat treatments were carried out with specimens $H, I$ and $J$; holding at $950^{\circ} \mathrm{C}$, under a cyclic heating of $950^{\circ} \rightleftarrows 800^{\circ} \mathrm{C}$ in the austenite region, and $950^{\circ} \rightleftarrows 700^{\circ} \mathrm{C}$ including the critical range. Experimental results are compared as shown in Fig. 2. During an isothermal heating at $950^{\circ} \mathrm{C}$, the specimen $H$ contracted at the beginning, and did not change its length until 100 minutes had past. Under a cyclic heating in the austenite region, however, its length increased step by step irreversively. The dilatometer curves are shown in Fig. 3. Further growth was noticed during a cyclic heating of $950^{\circ} \rightleftarrows$ $700^{\circ} \mathrm{C}$ as shown in Fig. 2. At the beginning of an 3 isothermal heating, the specimen $I$ contracted about

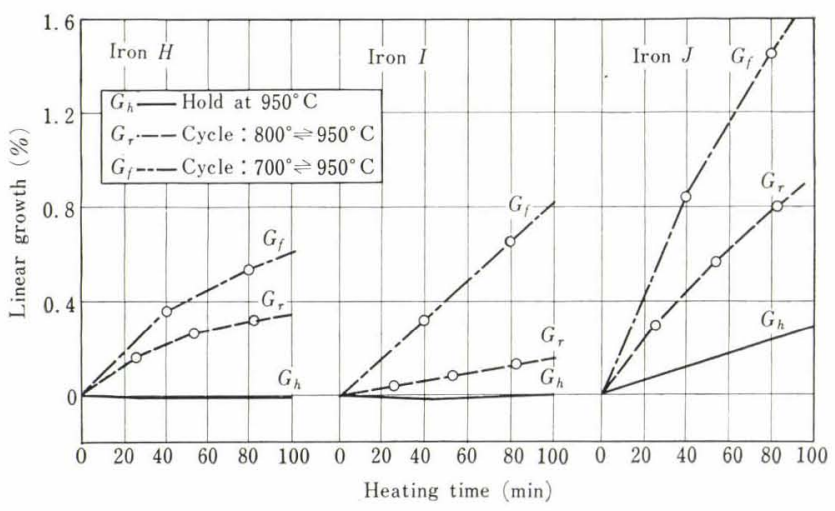

Fig. 2. Growth under different heat treatments

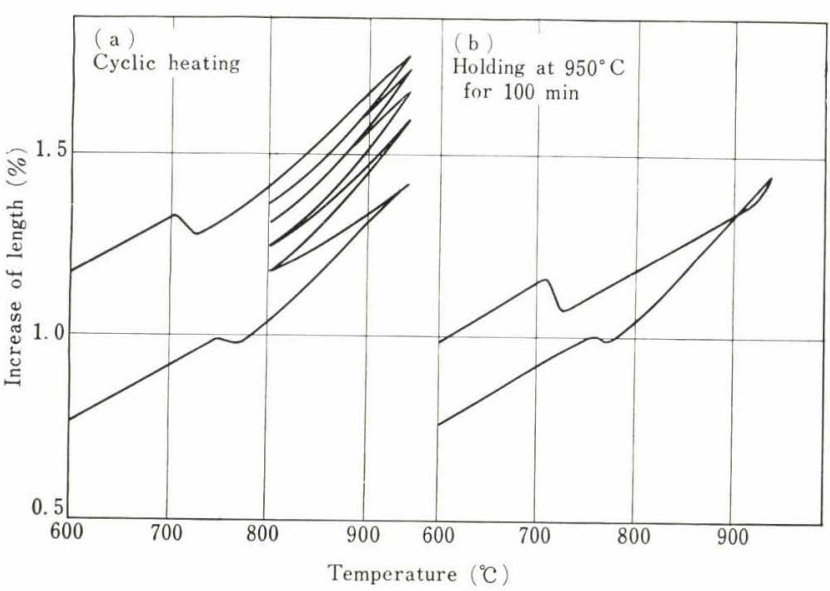

Fig. 3. Dilatometer curves indicating the growth in the austenite region

$0.02 \%$ in length, but recovered its initial length in 100 minutes. The growth of this iron in the austenite region was less than that of specimen $H$. In the temperature range covering the transformation, on the other hand, the growth of specimen $I$ was greater than that of specimen $H$. $H$ had a fine graphite microstructure and was harder than $I$. Specimen $J$ was the most coarse graphite grey iron and its length increased about $0.2 \%$ under a constant temperature of $950^{\circ} \mathrm{C}$. This specimen showed the most remarkable growth during a cyclic heating.

According to the earlier investigations, ${ }^{7), 2)}$ the expansion under a heating of constant temperature and the growth under a cyclic heating in the austenite region were regarded mainly as the increase of volume by internal oxidation. But the effects of heating and cooling on the growth obtained in the present investigation can not be explained by the oxidation theory. In other words, the growth of a coarse graphite iron was greater than that of a fine graphite iron in the critical range, but the trend was reversed in the austenite region. These facts can not clearly be explained as the oxidation effects. In the previous researches, wedges $^{2)}$ of oxidation products and protective zones ${ }^{8)}$ against oxidation were introduced to lend support to the oxidation theory and also to understand the phenomena of growth in cast iron. However, it is difficult to obtain an experimental proof for these models. The experimental results and the relations among them can be understood as some variations in migrating condition of carbon by the mechanism ${ }^{4)}$ of growth developed by the present author, which is based on the migration of graphite carbon.

Table 1. Chemical composition of the specimens $(\%)$

\begin{tabular}{|c|c|c|c|c|c|c|c|c|}
\hline Cast iron & $\mathrm{C}$ & $\mathrm{Si}$ & $\mathrm{Mn}$ & $\mathrm{P}$ & $\mathrm{S}$ & $\mathrm{Cr}$ & $\mathrm{Mg}$ & Remarks \\
\hline $\begin{array}{l}H \\
I \\
J \\
K \\
M \\
N \\
O \\
P \\
R \\
T\end{array}$ & $\begin{array}{l}3.33 \\
3.55 \\
3.63 \\
2.82 \\
3.35 \\
2.95 \\
3.78 \\
3.61 \\
3.15 \\
3.36\end{array}$ & $\begin{array}{l}1.08 \\
3.37 \\
3.47 \\
1.89 \\
1.62 \\
1.43 \\
1.33 \\
1.25 \\
1.47 \\
3.03\end{array}$ & $\begin{array}{l}0.30 \\
0.50 \\
0.54 \\
0.84 \\
0.45 \\
0.25 \\
0.57 \\
0.36 \\
0.76 \\
0.60\end{array}$ & $\begin{array}{l}0.140 \\
0.030 \\
0.200 \\
0.044 \\
0.310 \\
0.140 \\
0.291 \\
0.310 \\
0.074 \\
0.027\end{array}$ & $\begin{array}{l}0.078 \\
0.014 \\
0.024 \\
0.031 \\
0.048 \\
0.058 \\
0.091 \\
0.082 \\
0.117 \\
0.012\end{array}$ & $\begin{array}{l}- \\
- \\
- \\
- \\
- \\
- \\
- \\
0.45 \\
0.55 \\
-\end{array}$ & $\begin{array}{l}- \\
- \\
- \\
- \\
- \\
- \\
- \\
- \\
- \\
0.041\end{array}$ & $\begin{array}{l}\text { Inoculated } \\
\text { Pig iron } \\
\text { Inoculated } \\
\text { Inoculated }\end{array}$ \\
\hline
\end{tabular}




\section{Effects of Temperature Difference}

Some tests on the growth in the austenite region were performed with specimen $H$ for temperature differences of $50^{\circ}, 100^{\circ}$ and $150^{\circ} \mathrm{C}$ by fixing the lower limit of cyclic heating at $750^{\circ} \mathrm{C}$. The growth of these test pieces after five cycles of heating were $0.11,0.15$ and $0.26 \%$ at $7500^{\circ} \mathrm{C}$, and $0.17,0.25$ and $0.41 \%$ at room temperature. It was recognized that the growth in the austenite region increased in proportion to the temperature difference. As the average temperature of heating cycle becomes higher according to the increase of temperature difference, however, the experimental results obtained in air may be explained as the effects of oxidation.

A series of tests were also undertaken with specimen $K$ to examine the effects of temperature difference by fixing the upper limit of cyclic heating at a constant temperature. The heating cycles of the experiments are shown in Table 2. Total time of heating in air atmosphere was about 100 minutes in each test, and the results obtained are shown in Fig. 4. It can clearly be recognized that the growth in the austenite region depends on the difference of temperature in cyclic heating. Since the upper limit of temperature in this experiment was kept constant, the larger the temperature difference, the lower the average temperature. Therefore, oxidation effects were severe in the cases of less temperature difference. These results can not be explained by the previous theories.

Further tests were carried out on the effect of temperature with specimens $H$ and $K$ under a condition of constant temperature difference in heating cycle, and the results are shown in Table 3 . It was recognized in these tests that the growth in high temperature was not necessarily large when the temperature difference was constant. Since the amount of carbon which migrates during the cyclic heating

Table 2. Heating cycle of the experiments

\begin{tabular}{|c|c|c|c|}
\multicolumn{2}{c}{ Heat treatment $\left({ }^{\circ} \mathrm{C}\right)$} & $\begin{array}{c}\text { No. of } \\
\text { heating } \\
\text { cycles. }\end{array}$ & $\begin{array}{c}\text { Total heating } \\
\text { time } \\
\text { (min) }\end{array}$ \\
\hline $\begin{array}{c}\text { Difference } \\
\text { in temp. }\end{array}$ & Range of temp. & \\
\hline 0 & $950^{\circ} \mathrm{C}$, hold. & - & 100 \\
50 & $950 \rightleftharpoons 900$ & 9 & 109 \\
100 & $950 \rightleftharpoons 850$ & 6 & 105 \\
150 & $950 \rightleftharpoons 800$ & 4 & 100 \\
200 & $950 \rightleftharpoons 750$ & 3 & 95 \\
\hline
\end{tabular}

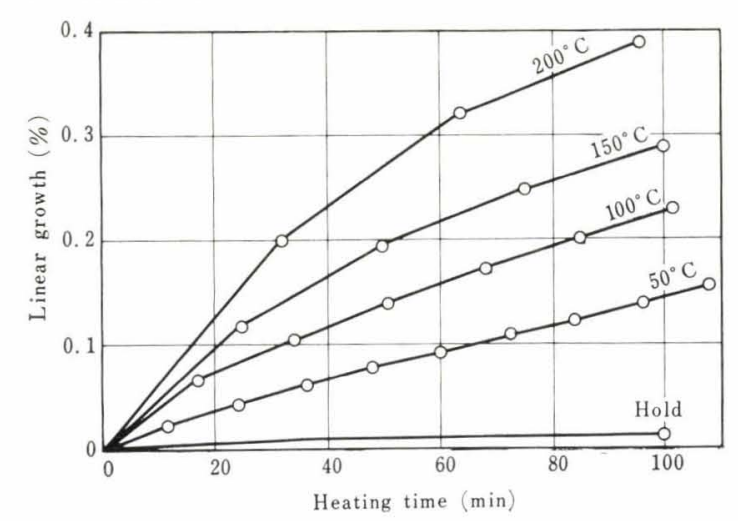

Fig. 4. Effects of temperature difference on the growth in the austenite region
Table 3. Effects of temperature on the growth in the austenite region

\begin{tabular}{|c|c|c|c|c|c|}
\hline \multirow[b]{2}{*}{ Cast iron } & \multirow{2}{*}{$\begin{array}{c}\text { Temperature } \\
\text { difference } \\
\left({ }^{\circ} \mathrm{C}\right)\end{array}$} & \multirow{2}{*}{$\begin{array}{c}\text { Heating } \\
\text { cycle } \\
\left({ }^{\circ} \mathrm{C}\right)\end{array}$} & \multirow{2}{*}{$\begin{array}{l}\text { No. of } \\
\text { cycles }\end{array}$} & \multicolumn{2}{|c|}{ Growth (\%) } \\
\hline & & & & Total & $\begin{array}{c}\text { Austenite } \\
\text { region** }\end{array}$ \\
\hline$H$ & 150 & $\begin{array}{l}800 \rightleftharpoons 950 \\
750 \rightleftharpoons 900\end{array}$ & $\begin{array}{l}5 \\
5\end{array}$ & $\begin{array}{l}0.40 \\
0.41\end{array}$ & $\begin{array}{l}0.28 \\
0.35\end{array}$ \\
\hline$K$ & 100 & $\begin{array}{l}850 \rightleftharpoons 950 \\
750 \rightleftharpoons 850\end{array}$ & $\begin{array}{l}7 \\
7\end{array}$ & $\begin{array}{l}0.41 \\
0.31\end{array}$ & $\begin{array}{l}0.16 \\
0.17\end{array}$ \\
\hline
\end{tabular}

process in the austenite region increases in proportion to the difference of temperature, it may be considered that the growth in the austenite region is related to the quantity of migrating carbon in the growing cycle.

\section{Growth of Hard Cast Iron}

Pearlite cast irons $H$ and $K$ both show a remarkable growth in the austenite region as shown in Figs. 3 and 4. A heat-resistant cast iron $R$ containing $0.55 \%$ chromium did not grow in the critical range, but some growth was observed in the austenite region for the cyclic heating. And the growth observed in the cycle covering both regions was fairly remarkable. According to the theory developed by Kikuta, ${ }^{1}$ a cast iron does not grow in its critical range so far as the pearlite structure is stable, because the degree of irregularity in volumetric change and the tendency of crack formation in the critical range become minimum when the transformation proceeds in stable pearlite and austenite without ferrite structure. The Kikuta theory may be applied for the growth characteristics of pearlite cast iron, but the growth in the austenite region of hard grey iron which does not grow in the critical range can not be explained. As no transformation exists in the austenite region, the growth has no relation to the stability of pearlite and the graphitization of carbide in grey iron does not generally take place in the austenite region. The facts that no growth in the critical range occurs and a growth appears in the austenite region can be understood from the migration of carbon only as a pehnomenon in physical metallurgy.

On the other hand, a redistribution of cementite was observed in the microstructure of grown hard cast iron after a cyclic heating. The redistribution of carbide is also a result of carbon migration that occurs during a cyclic heating process, but the migration of carbide carbon does not make the cast iron grow, because the coefficients of specific volume do not show a remarkable change in this case. Therefore, the stable carbide decreases the growth in the austenite region as the stable pearlite restricts the growth in the critical range. Some facts concerning this problem were previously reported ${ }^{4)}$ by the author.

\section{Effects of Graphite Structure}

The growth of cast iron is influenced by the graphite structure. Graphite flakes are regarded as the passages for oxygen penetration. Graphite flakes also 
act as notches in the structure and so weaken the cast iron as to make for crack formation. Consequently, it has been explained by these reasons that fine graphite cast iron and nodular graphite cast iron have excellent characteristics for growth by heating. But it is not adequate to derive conclusions concerning the effects of graphite structure from experimental results on some iron of different production method and different chemical composition. Some problems concerning the effects of graphite structure still remain for investigation.

The graphite structure varies in the size of flakes with the thickness of casting even though the compositions are the same. An experiment was performed on iron $I$, with two specimens of different graphite size. Namely, iron $I$ was casted into cylindrical moulds of $35 \mathrm{~mm}$ dia. and $25 \mathrm{~mm}$ dia. Each castings was then machined so that the test pieces were taken from the central part of each castings. A specimen from the larger castings had very coarse flake graphite and the matrix was ferritic in microstructure. Fine graphite flakes and pearlitic matrix were observed in the specimen casted into the smaller mould. The test pieces were heated and cooled in the cycles of $950^{\circ} \rightleftarrows 800^{\circ} \mathrm{C}$ in the austenite region and of $850^{\circ} \rightleftarrows 700^{\circ} \mathrm{C}$ in the critical range, each five times.

According to the results, the growth of coarse graphite iron was $0.19 \% /$ cycle and that of fine graphite iron was $0.13 \% /$ cycle both in the critical range, but their growth in the austenite region was about $0.06 \% /$ cycle and their difference was scarcely recognized. The structure of their matrix after the tests was entirely ferritic in both specimens. The remarkable growth of coarse graphite iron over the critical range, observed in the present experiment, coincides with previous investigations and may be understood by oxidation theory and cracking theory. But no difference in growth was observed in the austenite region. Namely, the size of graphite has no effect on the growth, and this result is not explained by oxidizing. The influence of oxidation may be more severe in the austenite region when the heating temperature is high. Therefore, if graphite flakes are passages for the penetration of oxidizing, the growth of coarse graphite cast iron must be more remarkable. Furthermore, if graphite flakes act as the internal notches which weaken the iron, the coincidence of the growth characteristics in the austenite region means that the notch effect of graphite flake must again be equal, so far as only the generation of cracking is considered. When oxidation and cracking are concerned with the growth, the notch effect of graphite flake must be less in coarse graphite iron, because oxidation is more severe in the austenite region. In conclusion neither oxidation nor crack formation gives a reasonable explanation for the growth in the austenite region. According to the present author's graphite redistribution theory, these results can be understood as the influences of graphite structure and the mechanism of carbon migration in heating. Outline of the growth of cast iron in the critical temperature range is discussed in $\boldsymbol{I I I}-6$ of this paper.
Concerning the growth of a nodular graphite cast iron, it was already reported $^{5}$ ) that the particular performance of the volume change in cyclic heating in the critical range could not be understood by the previous theory. This subject was investigated by an experiment on the growth in the austenite region. Nodular graphite cast iron $\mathcal{T}$ was heated and cooled in a cycle in its austenite region, critical range and the region covering both regions. Dilatometer curves are shown in Fig. 5. The trace of expansion and

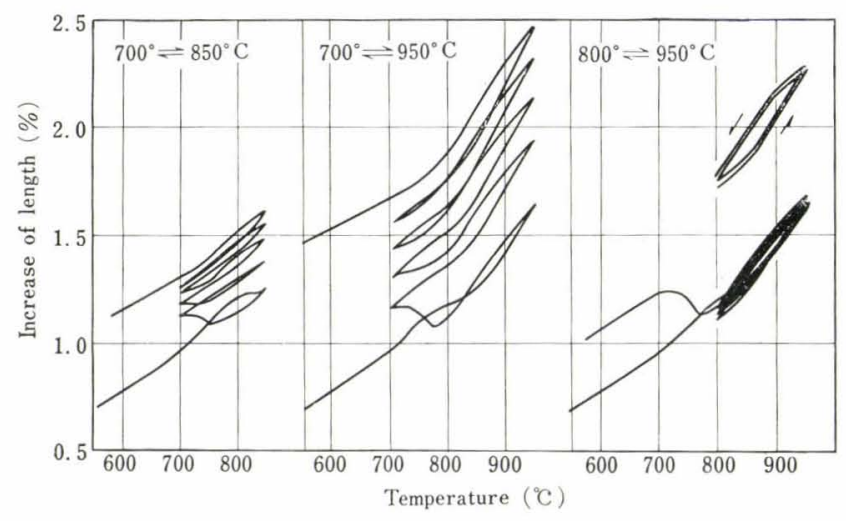

Fig. 5. Dilatometer curves of nodular graphite cast iron

contraction of the nodular cast iron caused by heating in its critical range became ambiguous and the thermal expansion curves changed into a very simple form in a few cycles. And the total expansion of the nodular cast iron by heating in the austenite region was larger than that of the other cast irons. The same phenomena were also observed in a dilation test of nodular cast iron previously carried out in vacuum. ${ }^{5}$ )

In the austenite region, the growth of the nodular cast iron was very little. Furthermore, it was recognized that the cooling curve obtained by a dilatometer was changed in its expanding side on the heating curve and that the curve was changed in its contracting side by the next heating. Namely, cyclic heating curves in the austenite region draw loops and the iron show a gradual growth as the histeresis of heating and cooling. It was mentioned by Sawamura $^{2)}$ in his paper on the growth of cast iron that the cooling curve changed irreversively to the expanding side by a cyclic heating and that this shift simply indicated the effect of oxidation caused by the wedges of the products of oxidation. But, such explanation concerning the irreversible change may not be applicable to the looping curve observed on the nodular cast iron. Generally speaking, therefore, the combined theory of oxidation and cracking does not work for the growth of cast iron. However, if the dilatometer curves indicate the change of volume introduced by carbon migration in a cyclic heating, the looping curve of nodular cast iron can be understood as the nominal change in volume resulted from some porosity remaining in it. An outline of this problem was considered by the present author and the reasonings of the looping curve in the austenite region and the disappearance of expansion and contraction in the critical temperature range were fairly well explained. ${ }^{9)}$ 


\section{Effect of Preheating}

Through some discussions on the experimental results, it was emphasized that an irreversible volume change in a cyclic heating must be introduced as a metallurgical phenomenon to be caused by the migration of graphite carbon which occurred by heating and cooling. But this conception does not mean to deny the expansion by graphitization of carbide and internal oxidation that produces bulky oxides. These phenomena are deeply related each other at high temperature. Especially, in heating in the austenite region, the influence of oxidizing atmosphere on the growth can not be ignored. According to some experimental results obtained in the earlier stage of this investigation, the iron which did not change its length during isothermal heating in the austenite region showed that the inclination of the cooling curve decreased in proportion to the length of isothermal holding time and the growth after cooling increased. The growth occurring in the period of isothermal heating may be regarded as the effect of atmosphere. But, the growth experienced in cooling is not due to the irreversible expansion resulting from the bulky oxides. So far as the effects of oxidizing gas such as oxygen are concerned, the obstructing effects on migration of carbon through the matrix should not be ignored, nor should the irreversible expansion by bulky oxides or the internal destruction by pressure of occluded gas.

Some experiments were performed to examine the effect of preheating on a cyclic growth in the austenite region and in the critical range. Iron $H$ was heated in air at $950^{\circ} \mathrm{C}$ for 100 minutes. After that growth tests were carried out with a preheated iron and an iron without preheating. Cycles of heating were $950^{\circ} \rightleftarrows 800^{\circ} \mathrm{C}$ in the austenite region and $850^{\circ} \rightleftarrows 700^{\circ} \mathrm{C}$ in the critical range. According to the result obtained, the growth in the austenite region increased about $48 \%$ by preheating in air, but decreased somewhat in the critical range. An experiment with a test piece preheated for 100 minutes in air at $850^{\circ} \mathrm{C}$ was then further undertaken to assure that the decrease of growth in the critical range was introduced by preheating. The increase of growth resulting from this preheating was not noticeable in the austenite region, but about $15 \%$ of decrease was seen in the critical range.

It is a noticeable fact that the treatment of preheating in air accelerates the growth in the austenite region and retards it in the critical temperature range. If all factors have similar influences upon the growth both in the austenite region and the critical range, the significance of the discrimination between the growth in the austenite region and that in the critical range is not important. But, the effects of preheating in air on growth, in other words the effects of oxidizing atmosphere, are different in the austenite region and in the critical range in the same way as the effects of graphite structure are. Consequently, although investigations on the growth in the austenite region had not ever been performed, the separation between these two different kinds of growth must first be understood before comprehending the growth in cast iron completely. Furthermore, the results obtained in the present study point out the inconsistency of the combined theory ${ }^{2)}$ on growth as was already discussed. It has been thought that a cracking accelerates the oxidation and wedges of oxides promote crack formation to increase the growth. But, as far as the effect of preheating in air is regarded as the effect of atmosphere oxidizing the metal and graphite, the decrease of growth in the critical range obviously introduced by preheating can not be explained. If the effect of preheating in air means the influence of gas absorbed into iron from the atmosphere while it is heated, the acceleration and retardation of the growth by preheating can be explained in the similar manner as the concept of explaining the decrease of carbon mobility in the matrix is accepted. When a cast iron is heated, carbon migrates through austenite in the austenite region and through ferrite in the critical temperature range. Retardation of mobility of carbon in the austenite region promotes the redistribution of graphite and the growth increase, but in the critical range the matrix changes into pearlite and the growth decreases. Retardation of carbon mobility has not yet been confirmed experimentally, but this conception seems to be more easily accepted than the theory proposed by Grant in his paper. ${ }^{6)}$ Grant has reported the double effects of oxidation on the growth-the effects of increase and decrease of growth. Of course, he believed that the oxidation accelerated the growth with bulky oxides. He introduced in his explanation of the restriction by oxidation a barrier of oxides produced at the surface of graphite flake which decreased the further growing.

\section{Relations between Growth in the Austenite Region and That in the Critical Range}

Growth of flake graphite cast irons was measured for the heating cycles of $950^{\circ} \rightleftharpoons 800^{\circ} \mathrm{C}$ in the austenite region, $850^{\circ} \rightleftharpoons 700^{\circ} \mathrm{C}$ in the critical temperature range, and $950^{\circ} \rightleftarrows 700^{\circ} \mathrm{C}$ covering both regions. Results are illustrated in Fig. 6 to show the relations among the growth in each different heating of five cycles. Growth in the critical range and that in the austenite region are indicated as $G_{\alpha}$ and $G_{\gamma}$, respectively. $G_{f}$ is a sign to show the growth in the cycle covering both cycles. The relation between growth $G_{\alpha}$ and $G_{f}$ is almost linear but the plottings are scat-
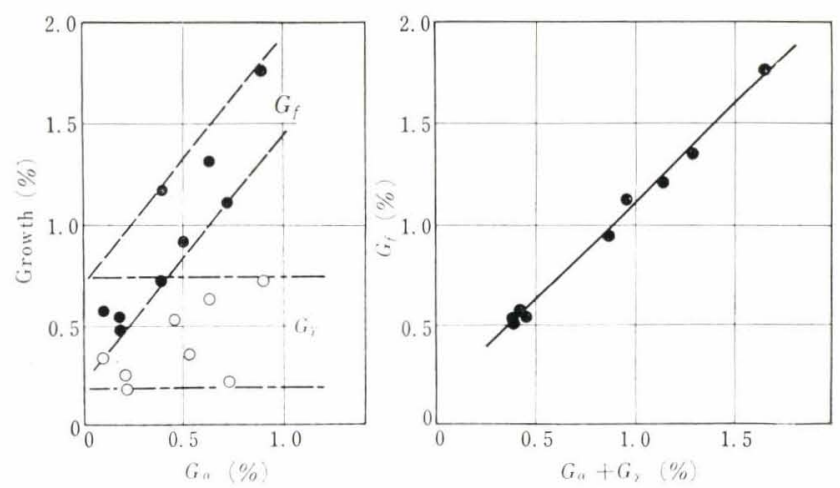

Fig. 6. Relation between the growth in the austenite region and that in the critical range 
tered. The relation between the two kinds of growth $G_{\alpha}$ and $G_{\gamma}$ can hardly be recognized. But the sum of the growth $G_{\alpha}+G_{\gamma}$ taken in a horizontal direction, has a very good linearity against $G_{f}$ in a vertical direction. Further, the experimental verifications show that the growth characteristics of cast iron were not similar in the austenite region and in the critical range. Some iron have reverse characteristics in both regions. And if a growth characteristics in the critical range $\left(G_{\alpha}\right)$ is similar, its growth in the region covering both regions $\left(G_{f}\right)$ is ruled by the growth in the austenite region $\left(G_{\gamma}\right)$. Even if the growth of some cast iron is similar in the heating cycle covering both regions, a quite remarkable difference may sometimes be observed in the other cycles.

In this experiment, the growth in the heating cycle of $850^{\circ} \rightleftarrows 700^{\circ} \mathrm{C}$ was regarded as being caused mainly by transformation. Strictly speaking, however, this growth contains that occurring in austenite region, because the critical temperature of $A_{c \cdot 1}$ is not identical with that of $A_{r \cdot 1}$. Therefore, the heating cycle only in the critical range excluding the austenite region can not be decided. The growth of $G_{\alpha}$ may approximately be equivalent to that caused by transformation only when temperature difference is very small. In previous investigations, the growth caused by transformation was submitted as the most important problem, but the growth examined as that resulting from transformation must usually include some degree of the growth in the austenite region. Therefore, the separation between the two kinds of growth in the transformation range and the austenite region must first be realized before a detailed discussion concerning the growth can be developed. But, it is almost hopeless to divide them directly by experiment, and an indirect method was attempted. In this experiment, the upper temperature of heating cycle was fixed and two values of temperature were selected at just over the critical temperature $A_{r \cdot 1}$ in the austenite region and at just below the critical temperature as the lower limits of the cycles. The difference in growth obtained in these two cycles was measured graphically on dilatometer curves after the test. The difference of growth thus obtained may be regarded as the separated growth due to transformation. Results obtained in such a manner are shown in Table 4. The tests were carried out on soft iron $J$ and hard iron $K$ of different graphite structures. As will naturally be expected, the experimental results showed that the growth due to transformation was remarkable in

Table 4. Growth by $A_{1}$ transformation

\begin{tabular}{|c|c|c|c|}
\hline Cast iron & Heating cycle $\left({ }^{\circ} \mathrm{C}\right)$ & Average growth $(\mathrm{mm})$ & Rate \\
\hline \multirow{4}{*}{$\begin{array}{c}K \\
\text { (Hard) }\end{array}$} & $700 \rightleftharpoons 850$ & $4.7 \times 1 / 100$ & 100 \\
\hline & $750 \rightleftharpoons 850$ & 2.6 & 55 \\
\hline & $700 \rightleftharpoons 950$ & 14.3 & 100 \\
\hline & $750 \rightleftharpoons 950$ & 9.3 & 65 \\
\hline \multirow{4}{*}{$\underset{\text { (Soft) }}{J}$} & $700 \rightleftharpoons 850$ & 23.7 & 100 \\
\hline & $780 \rightleftharpoons 850$ & 7.7 & 33 \\
\hline & $700 \rightleftharpoons 950$ & 38.5 & 100 \\
\hline & $800 \rightleftharpoons 950$ & 17.6 & $>45$ \\
\hline
\end{tabular}

soft cast iron and when the heating temperature was low. The growth in the austenite region, on the other hand, plays an important role in hard cast iron and at high temperature.

Some troubles in the technique of separating the growth due to transformation from the total growth can not be avoided. Namely, it is hard to clearly detect the critical temperature on the dilatometer curves and it is also difficult to measure the effect of the heating atmosphere in air. Critical points of cast iron can not clearly be noticed on the dilatometer curve as in the case of a steel. The duration of heating required for a cyclic heating, and the oxidizing effect as well, change depending upon whether the critical point in the cycle is included or excluded. Furthermore, the quantitative determination of the effect of atmosphere is hard to realize. However, it may be said in the present investgation that the growth occurring in the cycle covering the regions is nothing but a sum of the growth in each region. The growth due to transformation is usually accompanied by the growth in the austenite region.

\section{Conclusions}

As the phenomena of growth in cast iron are very complicated, many intricate theories of growth have been proposed. Transformation, graphitization and oxidation are concerned with the growth. The present author has further shown that the addition of the irreversible volume changes due to the migration of graphite carbon that occurs in a cyclic heat treatment should not be overlooked. Growth in the austenite region is mainly related to the migration of carbon in cyclic heating. In this paper, the experimental results explained are based upon a theory developed by the author to successfully confirm the new conception about the growth in cast iron. Relations between the growth in the austenite region and the growth in the critical range are very important problems. But discussion on the growth due to transformation are obviated, because unfortunately the information available on its detailed mechanism is as yet relatively meager.

As additional remarks, the author's mechanism developed after the present investigation elucidated that the growth due to the migration of graphite carbon is proportional to the quantity of migrating carbon, the porosity remaining after the diffusion of graphite into austenite, and the redistribution of graphite separated from matrix in the process of cooling.

The results obtained can be summarized as follows :

(1) A grey cast iron grows without transformation when it is subjected to a heating and cooling treatment in the austenite region.

(2) The growth in the austenite region depends mainly on the difference between the upper and lower temperatures of the heating cycle. However, it should not always be judged that a high temperature of heating increases the degree of growth even in the case of an equal temperature difference.

(3) Even a hard grey cast iron that does not grow 
in its critical range may grow in the austenite region.

(4) In some cast iron, a remarkable effect of graphite structure on growth is noticed in the critical range, but no effect can be seen in the austenite region.

(5) When a nodular graphite cast iron is subjected to a cyclic heating in its austenite region, it shows a gradual growth by drawing loops on its dilatometer curves.

(6) The growth of an iron preheated in air in its austenite region is larger than that without preheating, but the growth in its critical range is reduced by a treatment of preheating.

(7) Growth characteristics of a cast iron may differ in its critical and austenite regions. And the growth resulting from a cyclic heating at a temperature range covering both regions is the sum of the two kinds of growth in its separate regions.

(8) The growth due to transformation can not be examined independently, and it usually includes the growth in the austenite region.

(9) The effect of oxidizing atmosphere is indirect at the primary stage, but it increases the growth in the austenite region. This growth seems to be proceeded by a retardation of the mobility of carbon in matrix and an increase of the redistribution of graphite, both of which are introduced by the existence of the gas diffused into the iron from atmosphere. After that, the volume of cast iron may increase irreversibly by producing bulky oxides in its structure.

(10) Experimental facts concerning the growth of a cast iron in its austenite region can not be explained by the earlier theories. However, the con- ception of migration of carbons and redistribution of graphite in cast iron proposed by the present author clearly explains the mechanism of the growth.

(11) As an appendix, ${ }^{10)}$ a series of experiments were further undertaken to show that the growth in the austenite region could be seen in an atmosphere of vacuum or argon gas for both types of cast iron containing flake graphite and nodular graphite.

\section{Acknowledgements}

This investigation was performed in the laboratory of Hokkaido Industrial Institute. An Acknowledgement is made to the Institute. And the author wishes to express his indebtedness to Dr. I. Hagiwara for his instructive suggestions given in carrying out this investigation.

\section{REFERENCES}

1) T. Kitaka: Science Reports of the Tohoku Univ., (1922), 11 April 1-17.

2) H. Sawamura: Tetsu-to-Hagané, 23 (1937), 9, 863.

3) M. Ōkōchi and N. Satō: Memoirs of the Faculty of Eng. Tokyo Univ., 10.3 (1920), 2.

4) K. Nagaoka: Imono, 34 (1962), 5, 380.

5) K. Nagaoka: Tetsu-to-Hagané, 39 (1953), 11, 1250.

6) J. J. Grant: Foundry Trade J., 3 (1953), 9, 281.

7) S. Morita: Imono, 27 (1955), 4, 307.

8) M. M. Hallet: J. Iron G Steel Inst. (U.K.), 170 (1952), 321.

9) K. Nagaoka and I. Hagiwara: Tetsu-to-Hagané, 46 (1960), 10,1310 .

10) K. Nagaoka: Imono, 34 (1962), 9, 54. 